\title{
The impact of maternal employment on breast-feeding duration in the UK Millennium Cohort Study
}

\author{
Summer Sherburne Hawkins*, Lucy Jane Griffiths, Carol Dezateux, Catherine Law \\ and the Millennium Cohort Study Child Health Groupt \\ Centre for Paediatric Epidemiology and Biostatistics, Institute of Child Health, 30 Guilford Street, \\ London WCIN 1EH, UK
}

Submitted 25 January 2006: Accepted 25 April 2006: First published online 7 March 2007

\begin{abstract}
Objective: To examine the relationship of maternal employment characteristics, day care arrangements and the type of maternity leave pay to breast-feeding for at least 4 months.

Design: Cohort study.

Setting: Babies aged 9 months in the Millennium Cohort Study, born between September 2000 and January 2002.

Subjects: A total of 6917 British/Irish white employed mothers with singleton babies. Results: Mothers employed part-time or self-employed were more likely to breast-feed for at least 4 months than those employed full-time (adjusted rate ratio (aRR) and 95\% confidence interval (CI) $1.30(1.17-1.44)$ and $1.74(1.46-2.07)$, respectively). The longer a mother delayed her return to work postpartum, the more likely she was to breast-feed for at least 4 months $(P$ for trend $<0.001)$. Mothers were less likely to breast-feed for at least 4 months if they returned to work for financial reasons (aRR $0.86,95 \%$ CI 0.80-0.93) or used informal day care arrangements rather than care by themselves or their partner (aRR $0.81,95 \%$ CI $0.71-0.91$ ). Mothers were more likely to breastfeed for at least 4 months if their employer offered family-friendly (aRR 1.14, 95\% CI 1.02-1.27) or flexible work arrangements (aRR 1.24, 95\% CI 1.00-1.55), or they received Statutory Maternity Pay (SMP) plus additional pay during their maternity leave rather than SMP alone (aRR 1.13, 95\% CI 1.02-1.26). These findings were independent of confounding factors, such as socio-economic status and maternal education.

Conclusions: Current policies may encourage mothers to enter or return to employment postpartum, but this may result in widening inequalities in breastfeeding and persistence of low rates. Policies should aim to increase financial support and incentives for employers to offer supportive work arrangements.
\end{abstract}

Keywords
Breast-feeding
Employment
Public policy
Cohort studies
Maternal employment in the UK has increased rapidly in the last 10 years, with an 8\% increase in employment for married/co-habiting mothers with a pre-school child and an $11 \%$ increase for lone parents ${ }^{1}$. UK Government policies facilitate parental employment through financial support ${ }^{2}$, improved access to affordable day care $^{2}$ and flexible working ${ }^{3}$. Nearly $30 \%$ of mothers in the UK are returning to work by the time their baby is $4-5$ months old ${ }^{4}$. Against this background, the World Health Organization (WHO) recommends that babies should be exclusively breast-fed

†Other members of the Millennium Cohort Study Child Health Group: Professor Catherine Peckham (Professor), Professor Neville Butler (Professor), Professor Tim Cole (Professor), Dr Helen Bedford (Senior Lecturer), Dr A Rosemary Tate (Lecturer), Dr Suzanne Walton (Honorary Research Fellow), Dr Lamiya Samad (Research Fellow) and Suzanne Bartington (Research Assistant). for the first 6 months $^{5}$. Breast-feeding confers a range of health benefits for mothers and infants, as well as social and economic benefits ${ }^{6,7}$. Although breast-feeding rates have increased slightly in the UK since $1990^{4}$, the UK still has one of the lowest rates in Europe ${ }^{8}$. In 2000, 22\% of UK mothers breast-fed for at least 6 months, with only $1 \%$ of babies fed predominantly breast milk for that time period 9 .

There is limited research on the impact of maternal employment on breast-feeding duration. Studies from the USA have shown that employed mothers breast-feed for a shorter duration than non-employed mothers ${ }^{10-13}$ and that women are more likely to discontinue breast-feeding during the month that they begin employment ${ }^{14}$. A recent survey of UK mothers found that the shortest duration of breast-feeding was among women who returned to work when their baby was between 6 weeks and 4 months old ${ }^{4}$. The timing of entry into day care is also closely related to 
the timing of when a mother returns to employment. Evidence from the USA and Denmark suggests that babies in day care are breast-fed for a shorter duration than babies cared for at home $e^{15,16}$.

While differences in breast-feeding rates between employed and non-employed mothers have been reported, it is unclear whether and how factors in the workplace impact on breast-feeding duration among employed mothers. We analysed data from a recent, nationally representative cohort of mothers from all UK countries to examine how employment characteristics, day care arrangements and type of maternity leave pay are related to breast-feeding duration in women who return to work before their baby is 9 months old.

\section{Subjects and methods}

\section{Subjects and design}

The Millennium Cohort Study (MCS) is a UK-wide prospective study of the social, family, and health-related circumstances of children born in the new century. A stratified cluster sampling design was used to ensure an adequate representation of families living in disadvantaged areas and from ethnic minority groups. In England, electoral wards, as established in 1998, were categorised as 'ethnic', 'disadvantaged' or 'advantaged'. In Wales, Scotland and Northern Ireland, wards were classified as either 'disadvantaged' or 'advantaged'. Electoral wards in England were defined as 'ethnic' if at least 30\% of residents were from an ethnic minority group, based on 1991 census data; the remaining wards were categorised as either 'disadvantaged' (in the upper quartile of the Child Poverty Index) or 'advantaged'. Families were invited to participate if they were eligible for Child Benefit, a universal benefit available to all families, and were resident in the UK when the cohort child was aged 9 months ${ }^{17}$. The overall response rate was $72 \%{ }^{18}$.

The MCS comprises 18819 children (18 553 families) born between September 2000 and August 2001 in England and Wales, and between November 2000 and January 2002 in Scotland and Northern Ireland. The first contact with this cohort occurred when the infant was $\sim 9$ months old. Mothers and their partners were interviewed in the home and information was collected on infant feeding practices, employment, and individual and family characteristics.

Maternal ethnicity was self-reported and classified according to guidelines from the Office for National Statistics $^{19}$. White women were further categorised as British/Irish white if they were Caucasian of either British or Irish origin rather than being from any other European or other countries 9 . We have previously reported that British/ Irish white women are less likely to continue breast-feeding compared with mothers from ethnic minority groups? Thus, we examined data for 6917 employed British/Irish white natural mothers of singleton infants. Among these employed mothers, 1787 (26\%) were employed full-time (31+h/week), 4648 (67\%) part-time (1-30 h/week) and $482(7 \%)$ self-employed (for any number of hours).

\section{Outcome measure}

We examined breast-feeding duration, categorised as the proportion of all infants given any breast milk for at least 4 calendar months ( $\geq 17.4$ weeks). At the time of the MCS births, the WHO recommended that babies were breastfed for at least 4 months $^{8}$. In the MCS, only 608 (4\%) babies were fully breast-fed (receiving predominantly breast milk) for at least 4 months 9 . Our categorisation did not distinguish between babies who were fully or partially breast-fed.

\section{Employment characteristics}

Information was collected on when the mother returned to employment and hours worked. Working atypical hours was defined as working every week either in the evening, at night, at weekends, or away from home overnight.

Information was collected on reasons for starting or returning to employment postpartum. Women who gave an affirmative response to any of the following were categorised as working for financial reasons: 'returned to work because my Statutory Maternity Pay (SMP)/allowance/occupational maternity pay came to an end'; 'returned to work because I needed the money'; or 'in paid work because I am important as a breadwinner'. Mothers also stated if they returned to work because they had used up their maternity leave.

Maternal report of employer characteristics was used to define family-friendly arrangements (employer offering day care vouchers or assistance with day care) and flexible arrangements (employer offering part-time working, job sharing, flexible working hours or school-term contracts). The number of employees working for the mother's employer was also recorded.

\section{Day care arrangements and maternity leave pay}

Day care for the baby was categorised as informal (grandparents, other relatives, friends, neighbours), formal (nanny/au pair, childminder (registered or unregistered), nurseries or crèche (workplace, college, local authority or private)) or by the mother/partner ${ }^{20}$. Mothers also reported the type of pay, if any, that they had received during maternity leave. In 2000, UK employment policy entitled mothers to SMP which comprised 18 weeks of paid leave, with the first 6 weeks paid at 90\% of the woman's average weekly earnings, then $₫ 75$ per week for the next 12 weeks $^{21}$.

\section{Statistical analysis}

All analyses were conducted using STATA statistical software, version 8.2 (Stata Corporation), with sample weights and SVY commands to allow for the cluster 
sampling design and to obtain robust standard errors. Proportions were compared using Pearson's $\chi^{2}$ tests with the Rao and Scott second-order correction (significance $P \leq 0.05)^{22}$. Modified Poisson regression was used to calculate rate ratios for each variable listed above with respect to breast-feeding duration ${ }^{23}$. Analyses are presented before and after adjustment for the following potential confounding factors: mother's highest academic qualification, socio-economic status (classified according to the National Statistics Socio-economic Classification ${ }^{24}$ ), UK country, lone mother status (as reported at 9 months), age at MCS birth, age at first live birth and number of children in the household.

\section{Results}

Amongst the 6917 British/Irish white employed mothers, 1653 (25\%) breast-fed for at least 4 months, 5862 (86\%) had a highest academic qualification of GCSE grades A-C or above, 2753 (43\%) were in managerial or professional occupations and 1904 (25\%) in semi-routine and routine occupations, 515 (6\%) were lone mothers, mean age at MCS birth was 30 years, mean age at first live birth was 27 years, and 3437 (50\%) had one child living in the household. There were 3774 (54\%) employed mothers living in England, 1145 (17\%) living in Wales, 1086 (15\%) living in Scotland and 912 (13\%) living in Northern Ireland.

\section{Employment characteristics}

Women who worked part-time or were self-employed were more likely to breast-feed for at least 4 months than women who were employed full-time, after adjustment for confounding factors (Table 1). Self-employed mothers also returned to work earlier than mothers employed fulltime or part-time $(P<0.001)$ (data not shown). All subsequent analyses were also adjusted for employment status (full-time, part-time or self-employed).

Mothers who returned to work at or before 4 months were less likely to breast-feed for at least 4 months than mothers who returned to work later. However, women who returned to work at 6 months or later were more likely to breast-feed for at least 4 months. These effects were attenuated by adjustment for confounding factors, but remained statistically significant. The more hours a mother worked, the less likely she was to breast-feed for at least 4 months; this relationship strengthened after adjustment. Mothers who worked atypical hours were less likely to continue breast-feeding than those who did not, but this was not significant after adjustment. Mothers who returned to or started work for financial reasons were $14 \%$ less likely to breast-feed for at least 4 months, after adjustment. Working because the mothers' maternity leave was used up was not related to breast-feeding duration.

Mothers whose employer offered family-friendly or flexible work arrangements were more likely to breast-feed for at least 4 months than women whose employer did not offer these arrangements. Women who worked alone or in organisations with 25 or more employees were also more likely to continue breastfeeding than mothers who worked in small organisations (2-24 employees). These effects were attenuated by adjustment for confounding factors, but remained statistically significant.

\section{Day care arrangements and maternity leave pay}

Babies who were cared for by informal arrangements were less likely to be breast-fed for at least 4 months when compared with babies cared for by their mother or her partner; whereas, the proportion of babies breast-fed for at least 4 months did not differ between babies cared for by their mother or her partner and those cared for in formal day care arrangements, after adjustment. Mothers who received SMP plus additional pay during their maternity leave were more likely to breast-feed for at least 4 months than mothers who received only SMP. This relationship attenuated after adjustment, but remained statistically significant.

\section{Discussion}

We found that amongst British/Irish white mothers, women employed part-time or who are self-employed are more likely to breast-feed for at least 4 months than mothers employed full-time. Mothers are also less likely to breast-feed for at least 4 months the earlier they return to employment, if they return to work for financial reasons, work long hours or their baby is cared for by informal day care arrangements. In contrast, mothers are more likely to breast-feed for at least 4 months if they work alone, have an employer that offers supportive work arrangements or receive SMP plus additional pay during their maternity leave. These relationships were all apparent after adjustment for potential confounding factors, such as socio-economic status and maternal education.

The MCS afforded an opportunity to investigate associations between employment characteristics and breast-feeding duration amongst a diverse, nationally representative sample of white UK mothers who gave birth recently. We are unaware of other studies from the UK examining these relationships. Furthermore, previous studies have compared employed and non-employed women rather than examining the impact of employment circumstances among women who return to work. The breadth of data on employment in the MCS allowed us to identify factors related to breast-feeding duration that have not been reported on previously, including reasons for returning to employment, work place arrangements and type of maternity leave pay. Although information on infant feeding was collected retrospectively at 9 months postpartum, maternal recall of breast-feeding has been shown to be reliable and valid $^{25}$. 
Table 1 Weighted percentages and rate ratios (RRs) (95\% confidence intervals (CI)) for breastfeeding for at least 4 months among British/Irish white employed mothers

\begin{tabular}{|c|c|c|c|c|}
\hline & $n$ & $\begin{array}{l}\text { Breastfeeding for at least } \\
4 \text { months (weighted \%) }\end{array}$ & $\begin{array}{l}\text { Unadjusted } \\
\mathrm{RR}(95 \% \mathrm{Cl})\end{array}$ & $\begin{array}{c}\text { Adjusted }^{*} \\
\mathrm{RR}(95 \% \mathrm{Cl})\end{array}$ \\
\hline \multicolumn{5}{|l|}{ Employment characteristics } \\
\hline \multicolumn{5}{|l|}{ Employment status } \\
\hline Full-time & 1787 & 25 & 1.00 & 1.00 \\
\hline Part-time & 4648 & 26 & $1.03(0.91-1.16)$ & $1.30(1.17-1.44)$ \\
\hline Self-employed & 482 & 41 & $1.61(1.38-1.88)$ & $1.74(1.46-2.07)$ \\
\hline \multicolumn{5}{|l|}{ Return to employment } \\
\hline 3 months or less & 1204 & 18 & $0.82(0.69-0.99)$ & $0.81(0.68-0.96)$ \\
\hline 4 months & 1475 & 16 & $0.71(0.60-0.84)$ & $0.74(0.63-0.87)$ \\
\hline 5 months & 1244 & 22 & 1.00 & 1.00 \\
\hline 6 months & 874 & 32 & $1.43(1.21-1.69)$ & $1.25(1.07-1.47)$ \\
\hline 7 months & 1031 & 39 & $1.76(1.54-2.02)$ & $1.53(1.34-1.74)$ \\
\hline 8 months or more & 1064 & 39 & $1.74(1.49-2.03)$ & $1.54(1.36-1.73)$ \\
\hline \multicolumn{5}{|l|}{ Number of hours working } \\
\hline $1-10 h$ & 676 & 34 & 1.00 & 1.00 \\
\hline $11-20 \mathrm{~h}$ & 2499 & 25 & $0.75(0.66-0.85)$ & $0.79(0.70-0.90)$ \\
\hline $21-30 h$ & 1832 & 28 & $0.82(0.70-0.97)$ & $0.68(0.58-0.79)$ \\
\hline $31-40 \mathrm{~h}$ & 1578 & 25 & $0.75(0.64-0.88)$ & $0.63(0.45-0.90)$ \\
\hline $41+\mathrm{h}$ & 327 & 28 & $0.84(0.67-1.06)$ & $0.63(0.43-0.92)$ \\
\hline \multicolumn{5}{|l|}{ Working atypical hours } \\
\hline Yes & 2931 & 25 & $0.89(0.81-0.98)$ & $1.05(0.97-1.14)$ \\
\hline No & 3985 & 28 & 1.00 & 1.00 \\
\hline \multicolumn{5}{|l|}{ Working for financial reasons } \\
\hline Yes & 4918 & 25 & $0.76(0.70-0.84)$ & $0.86(0.80-0.93)$ \\
\hline No & 1999 & 32 & 1.00 & 1.00 \\
\hline \multicolumn{5}{|c|}{ Working because used up maternity leave } \\
\hline Yes & 2148 & 28 & $1.04(0.94-1.16)$ & $1.01(0.92-1.11)$ \\
\hline No & 4757 & 27 & 1.00 & 1.00 \\
\hline \multicolumn{5}{|c|}{ Employer offers any family-friendly arrangements } \\
\hline Yes & 1004 & 37 & $1.56(1.39-1.75)$ & $1.14(1.02-1.27)$ \\
\hline No & 5395 & 24 & 1.00 & 1.00 \\
\hline \multicolumn{5}{|c|}{ Employer offers any flexible arrangements } \\
\hline Yes & 5777 & 27 & $1.43(1.07-1.91)$ & $1.24(1.00-1.55)$ \\
\hline No & 648 & 19 & 1.00 & 1.00 \\
\hline \multicolumn{5}{|l|}{ Number of employees } \\
\hline Works alone & 481 & 43 & $2.01(1.72-2.35)$ & $1.60(1.35-1.91)$ \\
\hline $2-24$ & 2256 & 21 & 1.00 & 1.00 \\
\hline 25 or more & 4163 & 28 & $1.32(1.18-1.47)$ & $1.15(1.05-1.27)$ \\
\hline \multicolumn{5}{|l|}{ Day care } \\
\hline \multicolumn{5}{|l|}{ Type of day care } \\
\hline Mother/partner & 1869 & 25 & 1.00 & 1.00 \\
\hline Informal & 2859 & 19 & $0.78(0.68-0.89)$ & $0.81(0.71-0.91)$ \\
\hline Formal & 1969 & 38 & $1.55(1.39-1.73)$ & $1.07(0.95-1.20)$ \\
\hline \multicolumn{5}{|l|}{ Maternity leave } \\
\hline \multicolumn{5}{|l|}{ Maternity leave pay } \\
\hline $\begin{array}{l}\text { Statutory Maternity Pay plus } \\
\text { additional pay }\end{array}$ & 3275 & 31 & $1.39(1.23-1.57)$ & $1.13(1.02-1.26)$ \\
\hline Statutory Maternity Pay only & 2406 & 23 & 1.00 & 1.00 \\
\hline Other pay & 173 & 39 & $1.71(1.31-2.23)$ & $1.27(0.98-1.63)$ \\
\hline None & 279 & 28 & $1.22(0.94-1.58)$ & $1.15(0.93-1.42)$ \\
\hline
\end{tabular}

*Adjusted for highest academic qualification, socio-economic status, UK country, lone mother status, age at birth of cohort child, age at first live birth, number of children in household and employment status.

Missing number of cases for: return to employment (25), number of hours working (5), working atypical hours (1), working because used up maternity leave (12), employer offers any family-friendly arrangements (518), employer offers any flexible arrangements (492), number of employees (17), type of day care (220) and maternity leave pay (784).

Although we cannot exclude the possibility of residual confounding, our analyses have used the detailed information available on individual and family characteristics to adjust for factors that potentially confound the relationship of employment with duration of breastfeeding, such as socio-economic status and maternal education. Many of these factors, such as lone mother status, age at first live birth and number of children in the household, have not been included in previous analyses $^{11,13}$.

Our results are consistent with previous research which found that women employed part-time are more likely to continue breast-feeding than mothers employed fulltime $^{13,14}$. We were also able to report this association separately for mothers who work alone or are selfemployed. We found that these women are more likely to 
breast-feed for longer than mothers employed full-time or part-time. Although formal evidence is lacking, characteristics of working alone or being self-employed may support women to continue breast-feeding. Our findings are also consistent with evidence that the timing of when a woman returns to employment is related to breast-feeding duration $^{10,14}$. We found that the earlier a mother returns to work, particularly 4 months or earlier, the less likely she is to breast-feed for at least 4 months. At the time of the MCS births, most mothers were eligible for $\sim 4$ months of paid maternity leave. Our results suggest that women who return to work within this time period are at particular risk of not breast-feeding for at least 4 months. Future research should explore how returning to work postpartum influences women's decision to discontinue breastfeeding. We did not have any information about the types of jobs women in our sample had or the nature of their workplaces. Further research is also needed on how these factors may influence whether a woman continues to breast-feed.

The limited evidence on workplace arrangements and breast-feeding shows conflicting results. Cohen and Mrtek found that a lactation programme allowed employed women to continue breast-feeding for at least 6 months at the same rate as women who were not employed ${ }^{26}$. However, in a small study by Gielen and colleagues, there were no differences in breast-feeding duration among women whose employer either accommodated breast milk expression or allowed mothers to leave work to breast-feed and women without access to these arrangements ${ }^{13}$. In contrast, we found that women who had an employer that offered assistance with day care or flexible work arrangements were more likely to continue breast-feeding. In our study, while $\sim 90 \%$ of mothers had employers that offered flexible work arrangements, only 16\% were offered family-friendly arrangements. Further research is needed to evaluate which employment policies increase breastfeeding duration and how they may be implemented.

Infants cared for in day care settings are less likely to be breast-fed than babies cared for at home ${ }^{15,16}$. We found that the type of day care was also important. Babies cared for by informal arrangements were less likely to be breast-fed for at least 4 months than babies cared for by their mother or her partner. Bick and colleagues found that women were more likely to stop breast-feeding if female relatives took care of the baby, and proposed that unsupportive relatives may influence when women stop ${ }^{27}$. Since increasing employment rates suggest that more babies will be entering day care at a young age, future work should examine how different day care arrangements can support breastfeeding, particularly as our results showed that formal day care was not associated with decreased rates of breastfeeding for at least 4 months.

Since the MCS babies were born, employment policies have changed. Current UK policy entitles women to 12 months of maternity leave, with the first 6 weeks of leave paid at a rate of $90 \%$ of a woman's average weekly earnings, then $\$ 106$ per week for the next 20 weeks ${ }^{28}$. Maternity leave does not guarantee that women will be able to remain away from employment. We found that women are less likely to breast-feed for at least 4 months the more hours they work, the earlier they return to work or if they return for financial reasons. Government policies may encourage mothers to enter or return to employment as a way of alleviating poverty ${ }^{2}$, but such policies could increase inequalities in breast-feeding.

The International Labour Organization (ILO) standards for protecting and supporting breast-feeding among working mothers recommend: (1) a minimum of 14 weeks of paid maternity leave; (2) entitlement to one or more breast-feeding breaks or the reduction of hours to breast-feed without loss of pay; and (3) job protection and non-discrimination for breast-feeding workers ${ }^{29}$. Although many European countries provide additional support for women, the UK and the USA do not comply with even the minimum recommendations. The UK remains the least compliant European Union country with ILO standards ${ }^{30}$.

Maternal employment rates are likely to increase in the UK and worldwide. Our findings suggest that employment policies need to support breast-feeding among women who return to employment, such as through breastfeeding-friendly work arrangements, or allow women to choose to delay entering employment, such as through increased financial assistance in the months after birth. These findings support recommendations that employment policy should be evidence based and incorporate child health indicators, including breast-feeding, $6,30,31$. Despite the health, social and economic benefits of breast-feeding ${ }^{6,7}$, current employment policies and cultural attitudes towards breastfeeding may continue to prevent women from breast-feeding to optimise infant health.

\section{Acknowledgements}

Ethics approval: The Millennium Cohort Study was approved by the London Multi Centre Research Ethics Committee. The present analyses did not require additional ethics approval.

Sources of funding: The Millennium Cohort Study is funded by grants to Professor Heather Joshi, director of the study from the ESRC and a consortium of government funders. There was no funding source for this study. L.J.G. is funded by an MRC Special Training Fellowship in Health Services and Health of the Public Research. Research at the Institute of Child Health and Great Ormond Street Hospital for Children NHS Trust benefits from R\&D funding received from the NHS Executive.

Authorship responsibilities: S.S.H. and C.L. contributed to the conception, study design, analysis and interpretation of the data, and first draft of the article. L.J.G. and C.D. contributed to the study design, analysis and interpretation of the data, and further drafting of the 
article. All authors have also seen and approved the final version. S.S.H. will act as guarantor for the paper.

Acknowledgements: We would like to thank all of the Millennium Cohort Study families for their cooperation, and the Millennium Cohort Study team at the Centre for Longitudinal Studies, Institute of Education, University of London.

\section{References}

1 Walling A. Families and Work. Labour Market Trends, July 2005. London: Office for National Statistics, 2005; 275-83.

2 HM Revenue \& Customs. Child Tax Credit and Working Tax Credit. London: HM Revenue \& Customs, 2005.

3 Department for Trade and Industry. Flexible Working: The Right to Request and the Duty to Consider. London: Department for Trade and Industry, 2003.

4 Hamlyn B, Brooker S, Oleinikova K, Wands S. Infant Feeding 2000. A Survey Conducted on Behalf of the Department of Health, the Scottish Executive, the National Assembly for Wales and the Department of Health, Social Services and Public Safety in Northern Ireland. London: The Stationery Office, 2002.

5 World Health Organization (WHO)/United Nations Children's Fund. Global Strategy for Infant and Young Child Feeding. Geneva: WHO, 2002.

6 Gartner LM, Morton J, Lawrence RA, Naylor AJ, O'Hare D, Schanler RJ, et al. Breastfeeding and the use of human milk. Pediatrics 2005; 115: 496-506.

7 Ball TM, Bennett DM. The economic impact of breastfeeding. Pediatric Clinics of North America 2001; 48: 253-62.

8 Michaelsen KF, Weaver L, Branca F, Robertson A. Feeding and Nutrition of Infants and Young Children: Guidelines for the WHO European Region, with Emphasis on the Former Soviet Countries. Copenhagen: World Health Organizaton, 2003.

9 Griffiths LJ, Tate AR, Dezateux C. The Millennium Cohort Study Child Health Group. The contribution of parental and community ethnicity to breastfeeding practices: evidence from the Millennium Cohort Study. International Journal of Epidemiology 2005; 34: 1378-86.

10 Visness CM, Kennedy KI. Maternal employment and breastfeeding: findings from the 1988 national maternal and infant health survey. American Journal of Public Health 1997; 87: $945-50$.

11 Fein SB, Roe B. The effect of work status on initiation and duration of breast-feeding. American Journal of Public Health 1998; 88: 1042-6.

12 Kurinij N, Shiono PH, Ezrine SF, Rhoads GG. Does maternal employment affect breast-feeding? American Journal of Public Health 1989; 79: 1247-50.

13 Gielen AC, Faden RR, O'Campo P, Brown H, Paige DM. Maternal employment during the early postpartum period: effects on initiation and continuation of breast-feeding. Pediatrics 1991; 87: 298-305.

14 Lindberg LD. Women's decisions about breastfeeding and maternal employment. Journal of Marriage and the Family 1996; 58: 239-51.

15 Li R, Darling N, Maurice E, Barker L, Grummer-Strawn LM. Breastfeeding rates in the United States by characteristics of the child, mother, or family: the 2002 national immunization survey. Pediatrics 2005; 115: e31-7.

16 Weile B, Rubin DH, Krasilnikoff PA, Kuo HS, Jekel JF. Infant feeding patterns during the first year of life in Denmark: factors associated with the discontinuation of breast-feeding. Journal of Clinical Epidemiology 1990; 43: 1305-11.

17 Dex S, Joshi H, ed. Babies of the New Millennium. London: Policy Press, 2005.

18 Plewis I. Millennium Cohort Study: Technical Report on Sampling. London: Institute of Education, University of London, 2004.

19 Office for National Statistics. Ethnic Group Statistics: A Guide for the Collection and Classification of Ethnicity Data. London: The Stationery Office, 2003.

20 Brewer M, Shaw J. Childcare Use and Mothers' Employment: A Review of British Data Sources. London: Department for Work and Pensions, 2004.

21 Maternity and Paternity Leave etc. Regulations 1999, Statutory Instrument, 1999 No. 3312 (15 December 1999).

22 Rao JNK, Scott AJ. On chi-squared tests for multiway contingency-tables with cell proportions estimated from survey data. Annals of Statistics 1984; 12: 46-60.

23 Zou G. A modified Poisson regression approach to prospective studies with binary data. American Journal of Epidemiology 2004; 159: 702-6.

24 Rose D, Pevalin D. A Researcher's Guide to the National Statistics Socio-economic Classification. London: Sage Publications, 2003.

25 Li R, Scanlon KS, Serdula MK. The validity and reliability of maternal recall of breastfeeding practice. Nutrition Reviews 2005; 63: 103-10.

26 Cohen R, Mrtek MB. The impact of two corporate lactation programs on the incidence and duration of breast-feeding by employed mothers. American Journal of Health Promotion 1994; 8: 436-41.

27 Bick DE, MacArthur C, Lancashire RJ. What influences the uptake and early cessation of breast feeding? Midwifery 1998; 14: 242-7.

28 Department of Trade and Industry. Maternity Rights. Middlesex, UK: Acas Publications, 2003.

29 Maternity Protection Convention C183. Geneva: International Labour Organization, 2000.

30 Cattaneo A, Yngve A, Koletzko B, Guzman LR. Protection, promotion and support of breast-feeding in Europe: current situation. Public Health Nutrition 2005; 8: 39-46.

31 Galtry J. Child health: an underplayed variable in parental leave policy debates? Community, Work and Family 2002; 5: $257-78$. 